\title{
On a Method for Obtaining Iterative Formulas of Higher Order
}

\author{
Dragomir Simeunović
}

\begin{abstract}
In this paper a method for obtaining iterative formulas of higher order for finding roots of equations is obtained. These formulas include several already known results.
\end{abstract}

\section{INTRODUCTION}

Let

$$
x_{n+1}=f\left(x_{n}\right), \quad n=0,1,2, \ldots
$$

be an iterative method for finding the root $x=\alpha$ of the real or complex equation $F(x)=0$.

For the iterative method (1) which converges to $x=\alpha$, we say it is of order $k$ if

$$
\left|x_{n+1}-\alpha\right|=O\left(\left|x_{n}-\alpha\right|^{k}\right), \quad n \rightarrow \infty .
$$

If the function $f(x)$ is $k$ times differentiable in a neighborhood of the limit point $x=\alpha$, then the iterative method (1) is of order $k$ if and only if

$$
f(\alpha)=\alpha, \quad f^{\prime}(\alpha)=f^{\prime \prime}(\alpha)=\cdots=f^{(k-1)}(\alpha)=0, \quad f^{(k)}(\alpha) \neq 0 .
$$

This paper deals with a general method for obtaining iterative formulas of higher order.

\section{A Theorem for Iterative Formulas of Higher Order}

Starting from an iterative method of order $k \geq 1$ for finding the root $x=\alpha$ of the real or complex equation $F(x)=0$, we give, in this paper, a method for obtaining iterative formulas of order $\geq k+1$. In this connection the following theorem is proved here.

Theorem 1. Let (1) be an iterative method of order $k \geq 1$. Let the function $f(x)$ be $k+1$ times differentiable in a neighborhood of the limit point $x=\alpha$ and let

1991 Mathematics Subject Classification. Primary: 65H05.

Key words and phrases. Iteration formulas, approximate solutions of equations. 
$f^{\prime}(\alpha) \neq 1$. Then for the function $h(x) k$ times differentiable in the neighborhood of the limit point $x=\alpha$ such that

$$
h(\alpha)=0
$$

and

$$
h^{\prime}(\alpha)=1,
$$

formula

$$
x_{n+1}=f\left(x_{n}\right)-\frac{1}{k} f^{\prime}\left(x_{n}\right) h\left(x_{n}\right), \quad n=0,1,2, \cdots
$$

is an iterative method of order $\geq k+1$.

Proof. In the method (1) the iteration function is $f(x)$, and in the method (6) the iteration function is

$$
g(x)=f(x)-\frac{1}{k} f^{\prime}(x) h(x) .
$$

For the function $g(x)$ we shall prove that

$$
g(\alpha)=\alpha, \quad g^{\prime}(\alpha)=g^{\prime \prime}(\alpha)=\cdots=g^{(k)}(\alpha)=0 .
$$

By hypothesis, (1) is an iterative method of order $k \geq 1$ and therefore the relations (3) hold.

From (7) we have

$$
\begin{aligned}
g^{(r)}(x) & =f^{(r)}(x)-\frac{1}{k}\left(f^{(r+1)}(x) h(x)+r f^{(r)}(x) h^{\prime}(x)+\right. \\
& \left.+\left(\begin{array}{l}
r \\
2
\end{array}\right) f^{(r-1)}(x) h^{\prime \prime}(x)+\cdots+f^{\prime}(x) h^{(r)}(x)\right) .
\end{aligned}
$$

For $k \geq 1$, in view of (3) and (4), we obtain from (7)

$$
g(\alpha)=\alpha .
$$

Because of (3) and (4), we obtain from (9)

$$
g^{(r)}(\alpha)=0, \quad \text { textfor } \quad 1 \leq r \leq k-1,
$$

that is

$$
g^{\prime}(\alpha)=0, g^{\prime \prime}(\alpha)=0, \cdots, g^{(k-1)}(\alpha)=0 .
$$

On account of (3), (4) and (5), for $r=k$, we obtain from (9)

$$
g^{(k)}(\alpha)=f^{(k)}(\alpha)-\frac{1}{k} \cdot k f^{(k)}(\alpha)=0 .
$$

In view of (10), (11) and (12), we conclude that the relations (8) are satisfied for $k \geq 1$, which means that the iterative method (6) is of order $\geq k+1$. 


\section{Some Forms of the Function $h(x)$}

Taking for the function $h(x)$ different forms, we can obtain from (6) several particular results. Here we give some forms for the function $h(x)$.

3.1. For

$$
h(x)=\frac{u(x)}{u^{\prime}(x)} v(x),
$$

where the functions $u(x)$ and $v(x)$ are $k+1$ times differentiable in a neighborhood of the limit point $x=\alpha$ such that $u(\alpha)=0, u^{\prime}(\alpha) \neq 0$ and $v(\alpha)=1$, we have $h(\alpha)=0$ and $h^{\prime}(\alpha)=1$. In this case formula (6) reduces to

$$
x_{n+1}=f\left(x_{n}\right)-\frac{1}{k} f^{\prime}\left(x_{n}\right) \frac{u\left(x_{n}\right)}{u^{\prime}\left(x_{n}\right)} v\left(x_{n}\right), \quad n=0,1,2, \cdots .
$$

For different forms of the function $u(x)$ and $v(x)$, from (14) we can obtain the particular results.

3.1.1. For $u(x)=x-f(x)$ and $v(x)=1$, where $u(\alpha)=0, u^{\prime}(\alpha) \neq 0$, from (14) we obtain the iterative method

$$
\begin{aligned}
x_{n+1} & =f\left(x_{n}\right)-\frac{1}{k} f^{\prime}\left(x_{n}\right) \frac{x_{n}-f\left(x_{n}\right)}{1-f^{\prime}\left(x_{n}\right)}= \\
& =x_{n}-\left(1+\frac{1}{k} \frac{f\left(x_{n}\right)}{1-f^{\prime}\left(x_{n}\right)}\right)\left(x_{n}-f\left(x_{n}\right)\right), \quad n=0,1,2, \cdots,
\end{aligned}
$$

which is the result obtained in [7].

3.1.2. For $u(x)=x-f(x)$ and

$$
v(x)=\frac{1-f^{\prime}(x)}{1-\frac{1}{k} f^{\prime}(x)},
$$

where $u(\alpha)=0, u^{\prime}(\alpha) \neq 0$ and $v(\alpha)=1$, from (14) we obtain the iterative method

$$
\begin{aligned}
x_{n+1} & =f\left(x_{n}\right)-f^{\prime}\left(x_{n}\right) \frac{x_{n}-f\left(x_{n}\right)}{k-f^{\prime}\left(x_{n}\right)}= \\
& =x_{n}-\frac{x_{n}-f\left(x_{n}\right)}{1-\frac{1}{k} f^{\prime}\left(x_{n}\right)}, \quad n=0,1,2, \cdots,
\end{aligned}
$$

which is the result obtained by B. Jovanovic [4].

3.2. Let $x=\alpha$ is single root of the equation $F(x)=0$ and let the function $F(x)$ is $k+1$ times differentiable in a neighbourhood of the limit point $x=\alpha$. Then we have $F(\alpha)=0$ and $F^{\prime}(\alpha) \neq 0$.

For $u(x)=F(x)$, from (13) we obtain

$$
h(x)=\frac{F(x)}{F^{\prime}(x)} v(x),
$$

where $h(\alpha)=0$ and $h^{\prime}(\alpha)=1$. In this case formula (6) reduces to

$$
x_{n+1}=f\left(x_{n}\right)-\frac{1}{k} f^{\prime}\left(x_{n}\right) \frac{F\left(x_{n}\right)}{F^{\prime}\left(x_{n}\right)} v\left(x_{n}\right), \quad n=0,1,2, \cdots
$$


3.2.1. For $v(x)=1$, from (18) we obtain the iterative method

$$
x_{n+1}=f\left(x_{n}\right)-\frac{1}{k} f^{\prime}\left(x_{n}\right) \frac{F\left(x_{n}\right)}{F^{\prime}\left(x_{n}\right)}, \quad n=0,1,2, \cdots
$$

3.3. For $h(x)=x-f(x)$ and for $k \geq 2$ we have $h(\alpha)=0$ and $h^{\prime}(\alpha)=1$. In this case formula (6) reduces to

$$
\begin{aligned}
x_{n+1} & =f\left(x_{n}\right)-\frac{1}{k} f^{\prime}\left(x_{n}\right)\left(x_{n}-f\left(x_{n}\right)\right)= \\
& =x_{n}-\left(1+\frac{1}{k} f^{\prime}\left(x_{n}\right)\right)\left(x_{n}-f\left(x_{n}\right)\right), \quad n=0,1,2, \cdots
\end{aligned}
$$

which is the result obtained by G. Milovanović [5].

\section{EXAMPLES}

1) Let (1) be regula falsi, which means

$$
x_{n+1}=\frac{a F\left(x_{n}\right)-x_{n} F(a)}{F\left(x_{n}\right)-F(a)}, \quad n=0,1,2, \cdots
$$

where

$$
f(x)=\frac{a F(x)-x F(a)}{F(x)-F(a)} .
$$

The method (21) is of order $k=1$.

For $v(x)=\frac{F(x)-F(a)}{-F(a)}$, where $v(\alpha)=1$, from (18) we obtain Newton's iterative method of order $k=2$ for finding of the single root $x=\alpha$ of the equation $F(x)=0$, namely

$$
x_{n+1}=x_{n}-\frac{F\left(x_{n}\right)}{F^{\prime}\left(x_{n}\right)}, \quad n=0,1,2, \cdots
$$

2) If (1) represents Newton's method (22) for finding a single root $x=\alpha$ of the equation $F(x)=0$, which means that

$$
f(x)=x-\frac{F(x)}{F^{\prime}(x)}
$$

and $k=2$, then we obtain from (18) the iterative method

$$
x_{n+1}=x_{n}-\frac{F\left(x_{n}\right)}{F^{\prime}\left(x_{n}\right)}\left(1+\frac{F\left(x_{n}\right) F^{\prime \prime}\left(x_{n}\right)}{2\left(F^{\prime}\left(x_{n}\right)\right)^{2}} v\left(x_{n}\right)\right), \quad n=0,1,2, \cdots
$$

According to Theorem 1, the iterative method (23) is of order $k \geq 3$, since as we know Newton's method (22) is of order 2.

For different forms of the function $v(x)$, from $(23)$ we can obtain particular results. 
a) For $v(x)=1$, we obtain from $(23)$

$$
x_{n+1}=x_{n}-\frac{F\left(x_{n}\right)}{F^{\prime}\left(x_{n}\right)} \frac{2\left(F^{\prime}\left(x_{n}\right)\right)^{2}+F\left(x_{n}\right) F^{\prime \prime}\left(x_{n}\right)}{2\left(F^{\prime}\left(x_{n}\right)\right)^{2}}, \quad n=0,1,2, \cdots
$$

which is Chebyshev's method (see [1]).

b) For

$$
v(x)=\frac{2\left(F^{\prime}(x)\right)^{2}}{2\left(F^{\prime}(x)\right)^{2}-F(x) F^{\prime \prime}(x)},
$$

we obtain from $(23)$

$$
x_{n+1}=x_{n}-\frac{F\left(x_{n}\right)}{F^{\prime}\left(x_{n}\right)} \frac{2\left(F^{\prime}\left(x_{n}\right)\right)^{2}}{2\left(F^{\prime}\left(x_{n}\right)\right)^{2}-F\left(x_{n}\right) F^{\prime \prime}\left(x_{n}\right)}, \quad n=0,1,2, \cdots
$$

which represents Halley's method (see $[2,3]$ ).

c) For

$$
v(x)=\frac{\left(F^{\prime}(x)\right)^{2}}{\left(F^{\prime}(x)\right)^{2}-F(x) F^{\prime \prime}(x)},
$$

we obtain from $(23)$

$$
x_{n+1}=x_{n}-\frac{F\left(x_{n}\right)}{F^{\prime}\left(x_{n}\right)} \frac{2\left(F^{\prime}\left(x_{n}\right)\right)^{2}-F\left(x_{n}\right) F^{\prime \prime}\left(x_{n}\right)}{2\left(F^{\prime}\left(x_{n}\right)\right)^{2}-2 F\left(x_{n}\right) F^{\prime \prime}\left(x_{n}\right)}, \quad n=0,1,2, \cdots
$$

which is the method obtained in [7].

d) For

$$
v(x)=\frac{2}{\left(1-\frac{F(x) F^{\prime \prime}(x)}{\left(F^{\prime}(x)\right)^{2}}\right)^{\frac{1}{2}}\left(1+\left(1-\frac{F(x) F^{\prime \prime}(x)}{\left(F^{\prime}(x)\right)^{2}}\right)^{\frac{1}{2}}\right)},
$$

we obtain from $(23)$

$$
x_{n+1}=x_{n}-\frac{F\left(x_{n}\right)}{F^{\prime}\left(x_{n}\right)}\left(1-\frac{F\left(x_{n}\right) F^{\prime \prime}\left(x_{n}\right)}{\left(F^{\prime}\left(x_{n}\right)\right)^{2}}\right)^{-\frac{1}{2}}, \quad n=0,1,2, \cdots,
$$

which represents Ostrowski's square root method (see [6]).

e) For

$$
v(x)=\frac{2 m}{\left(1+(m-1)\left(1-\frac{m}{m-1} \frac{F(x) F^{\prime \prime}(x)}{\left(F^{\prime}(x)\right)^{2}}\right)^{\frac{1}{2}}\right)\left(1+\left(1-\frac{m}{m-1} \frac{F(x) F^{\prime \prime}(x)}{\left(F^{\prime}(x)\right)^{2}}\right)^{\frac{1}{2}}\right)},
$$

when $F(x)$ is a polynomial of degree $m \geq 2$, we obtain from (23)

(28) $x_{n+1}=x_{n}-\frac{F\left(x_{n}\right)}{F^{\prime}\left(x_{n}\right)} \frac{m}{1+(m-1)\left(1-\frac{m}{m-1} \frac{F\left(x_{n}\right) F^{\prime \prime}\left(x_{n}\right)}{\left(F^{\prime}\left(x_{n}\right)\right)^{2}}\right)^{\frac{1}{2}}}, \quad n=0,1, \cdots$

which is the Laguerre's method (see [3]). 
f) For

$$
v(x)=\frac{2( \pm 1)}{\left( \pm\left(1-( \pm 1) \frac{F(x) F^{\prime \prime}(x)}{\left(F^{\prime}(x)\right)^{2}}\right)^{\frac{1}{2}}\right)\left(1+\left(1-( \pm 1) \frac{F(x) F^{\prime \prime}(x)}{\left(F^{\prime}(x)\right)^{2}}\right)^{\frac{1}{2}}\right)}
$$

where $\beta$ is fixed finite parameter, we obtain from (23)

$$
x_{n+1}=x_{n}-\frac{F\left(x_{n}\right)}{F^{\prime}\left(x_{n}\right)} \frac{ \pm 1}{ \pm\left(1-( \pm 1) \frac{F\left(x_{n}\right) F^{\prime \prime}\left(x_{n}\right)}{\left(F^{\prime}\left(x_{n}\right)\right)^{2}}\right)^{\frac{1}{2}}}, \quad n=0,1,2, \cdots
$$

which represents a one parameter family of iterative formulas obtained by E. Hansen and M. Patrick [3].

In all previous cases we have $v(\alpha)=1$.

\section{REFERENCES}

[1] И. С. Березин, Н. П. Жидков, Методю вючислений, том ІІ. Государственное издательство физико-математической литературы, Москва 1960.

[2] M. Davies, B. Dawson, On the global convergence of Halley's iteration formula, Numer. Math. 24(1975), 133-135.

[3] E. Hansen, M. Patrick, A family of root finding methods, Numer. Math. 27(1977), 257-269.

[4] B. Jovanović, A method for obtainig iterative formulas of higher order, Mat. Vesnik $\mathbf{9}(\mathbf{2 4})(1972), 365-369$.

[5] G. V. Milovanović, A method to accelerate iterative processes in Banach space, Univ. Beograd. Publ. Elektrotehn. Fak. Ser. Mat. Fiz. N461 - Nº497(1974), 67-71.

[6] A. M. Ostrowski, Solution of equations and systems of equations, Second edition, Academic Press, New York and London 1966.

[7] D. M. Simeunović, On a process for obtaining iterative formulas of higher order for roots of equations, Anal. Num. Theor. Approx., 24(1995), 225-229. 